Check for updates

Cite this: RSC Adv., 2018, 8, 29455

Received 27th June 2018

Accepted 4th August 2018

DOI: $10.1039 / c 8 \mathrm{ra05507f}$

rsc.li/rsc-advances

\section{Three-channel capillary NF membrane with PAMAM-MWCNT-embedded inner polyamide skin layer for heavy metals removal $\uparrow$}

\author{
Hai-Zhen Zhang, Zhen-Liang Xu (D)* and Jing-Ying Sun
}

Nanofiltration (NF) membranes with simultaneous high rejection of divalent cations and anions and high water permeation were designed and fabricated via interfacial polymerization (IP) on three-channel capillary ultrafiltration (UF) membranes. MWCNTs-COOH were modified with poly(amidoamine) (PAMAM) and the as-synthesized MWCNTs-PAMAM were embedded into the inner polyamide skin-layer of the NF membranes by incorporating them into a piperazine (PIP) aqueous solution, followed by IP with trimesoyl chloride (TMC). The rigid MWCNTs and the dendrimer PAMAM molecules endow the asfabricated NF membranes with high porosity and good hydrophilicity. Additionally, the $-\mathrm{NH}_{2}$ groups of PAMAM introduce some positive sites into the polyamide layer. The as-prepared NF membranes with incorporated MWCNTs-PAMAM exhibit a pure water flux of $48.7 \mathrm{~L} \mathrm{~m}^{-2} \mathrm{~h}^{-1}$ and $92.6 \%$ and $88.5 \%$ rejection for $\mathrm{Na}_{2} \mathrm{SO}_{4}$ and $\mathrm{MgCl}_{2}$, respectively, at 4 bar. Moreover, the NF membranes display high rejection for sulfates and metal cations, including heavy metal ions. The practicability of the membranes for mine-wastewater treatment was tested, and the membranes showed above $80 \%$ rejection of heavy metals and solution flux of about $30 \mathrm{~L} \mathrm{~m}^{-2} \mathrm{~h}^{-1}$. In addition, their separation performance and stability were satisfactory during the long-term run. The high rejection of the membranes for metal cations is ascribed to the positive sites offered by MWCNTs-PAMAM and the narrow membrane pores since both electrostatic repulsion and size exclusion play a role during membrane filtration. The good separation performance of the membranes for multivalent anions and heavy metal cations illustrates their potential for applications in heavy metal wastewater treatment.

\section{Introduction}

The demand for clean water is a global issue due to water pollution and population growth, and the production of fresh water is currently a great challenge to society. ${ }^{\mathbf{1 , 2}}$ A sustainable way to alleviate this issue is wastewater reclamation and reuse. However, there are various contaminants in the wastewater discharged by industries including textile, electroplating, mining and coal-fired power plants. In particular, heavy metals are a serious threat to human health and the ecosystem. ${ }^{3,4}$

State Key Laboratory of Chemical Engineering, Membrane Science and Engineering $R \& D$ Lab, Chemical Engineering Research Center, East China University of Science and Technology (ECUST), 130 Meilong Road, Shanghai 200237, China. E-mail: chemxuzl@ecust.edu.cn; Fax: +86-21-64252989; Tel: +86-21-64253670

$\dagger$ Electronic supplementary information (ESI) available: The dispersion of original and modified MWCNTs in PIP aqueous solution (Fig. S1), FTIR spectra of the modified MWCNTs (Fig. S2), XPS spectra of the products of the original and MWCNTs modified with TMC (Fig. S3), effects of MWCNTs-PAMAM content on the performance of the NF membranes (Fig. S4), ATR-FTIR spectra of the membranes (Fig. S5), the performance of MPCP versus operation pressure (Fig. S6), membrane pure water flux vs. time (Fig. S7), adsorption capacity of the NF membranes (Fig. S8), and element contents of the reaction products of the original and MWCNTs modified with TMC (Table S1). See DOI: 10.1039/c8ra05507f
Soluble heavy metal ions are toxic and non-biodegradable and they can accumulate in living organisms, causing diseases and disorders. ${ }^{5}$ The current regulatory limit of the U.S. Environmental Protection Agency (EPA) for lead (Pb) is $15 \mathrm{ng} \mathrm{mL} \mathrm{m}^{-1}$ in drinking water, whereas the WHO has set a lower limit of $10 \mathrm{ng}$ $\mathrm{mL}^{-1}$ for $\mathrm{Pb}^{2+} \cdot{ }^{6}$ Moreover, the Chinese government has established stringent regulations for industrial wastewater discharge. Thus, the removal of heavy metals from wastewater is significant.

To remove heavy metals and recycle wastewater, diverse processing methods, which have both advantages and disadvantages, have been exploited, such as chemical precipitation, adsorption, ion exchange and membrane separation. ${ }^{7,8}$ Among these methods, membrane filtration is an alternative technology that can work in continuous operation and cause no secondary pollution; also, it can be used on both large and small scales. These advantages demonstrate that the membrane filtration technique has potential applications in the treatment of wastewater containing heavy metal ions. Nanofiltration (NF) membranes can effectively remove ions and small molecular organics from water due to the separation mechanisms of the Donnan effect and size exclusion. Heavy metals in wastewater are mainly in the form of cations $\left(\right.$ e.g. $\mathrm{Cd}^{2+}, \mathrm{Pb}^{2+}$, and $\left.\mathrm{Cu}^{2+}\right)$ and 
anions (e.g. $\mathrm{Cr}_{2} \mathrm{O}_{7}{ }^{2-}$ and $\mathrm{AsHO}_{4}{ }^{2-}$ ). Positively charged $\mathrm{NF}$ membranes can effectively remove cations, but they exhibit low rejection to anions due to the Donnan effect. Moreover, counterions and suspended colloids can foul these membranes during the filtration process because of the high surface charge density of the membranes. ${ }^{\mathbf{9 - 1 1}}$ Generally, negatively charged NF membranes are not suitable for removing heavy metal cations due to Donnan repulsion. Therefore, it is necessary to fabricate novel NF membranes for the removal of heavy metals from wastewater.

Ideal NF membranes for heavy metal removal should have a separation layer that contains a dual-layer with a positively charged underlayer and negatively charged upper layer. This is beneficial for both removing heavy metal ions and alleviating membrane fouling. A few researchers have focused on fabricating these dual- or mixed-charged NF membranes for heavy metal removal. Wu et al. prepared dual-charged NF membranes with a polyvinyl chloride (PVC) UF membrane as the substrate and piperazine (PIP) and trimesoyl chloride (TMC) as monomers. The resultant membranes exhibited high rejection for multivalent cations and anions; their rejection for $500 \mathrm{mg} \mathrm{L}^{-1}$ $\mathrm{Pb}^{2+}$ was $95.7 \%{ }^{11}$ Fang et al. fabricated polyamide-based NF membranes using PIP and polyethyleneimine (PEI) as monomers for water softening. The rejection of their NF membranes for $\mathrm{MgCl}_{2}, \mathrm{MgSO}_{4}$ and $\mathrm{Na}_{2} \mathrm{SO}_{4}$ was $96.3 \%, 93.8 \%$ and $77.4 \%$, respectively. ${ }^{12}$ Furthermore, there are some reports on the fabrication of NF membranes for cation and anion separation through two cycles of interfacial polymerization (IP), ${ }^{\mathbf{1 3}}$ coating $^{\mathbf{1 4}}$ and surface grafting. ${ }^{15}$ However, these NF membranes display a low permeation flux. Furthermore, the sustainable separation performance of NF membranes has rarely been reported.

Three channel-capillary membranes have unique advantages as substrates, such as superb strength and larger lumen surface areas compared with the traditional hollow fibers and flat membranes, which have been reported in our previous study. ${ }^{\mathbf{1 6}}$ PIP is usually used to fabricate negatively-charged NF membranes. ${ }^{17,18}$ Poly(amidoamine) (PAMAM) dendrimer consists of one central core, a branching structure and plentiful peripheral amine groups. Due to its unique three-dimensional structure and rich terminal amine groups, PAMAM can be easily modified and designed for various functions. ${ }^{19}$ It has been proven that PAMAM can increase the positive charge density and hydrophilicity of NF membranes. ${ }^{20}$ Permeability is important to NF membranes, and there are two main ways to achieve permeability: increasing the free volume and reducing the thickness of the separation layer. ${ }^{21}$ Multi-walled carbon nanotubes (MWCNTs) are confirmed to be effective in improving membrane permeability by improving the microporosity of the selective layers. ${ }^{22-25}$ To the best of our knowledge, there is no report on the use of composited MWCNTs-PAMAM for the fabrication of NF membranes. In this study, MWCNTsPAMAM were synthesized and characterized. In addition, a pathway for preparing NF membranes with a negatively charged selective layer containing positive sites is presented. PIP and MWCNTs-PAMAM were utilized as the monomer and additive in aqueous solution, respectively. The rigid MWCNTs and hydrophilic PAMAM endow the NF membranes with good permeability. In addition, the abundant $-\mathrm{NH}_{2}$ groups from PAMAM introduce positive sites into the selective layer of the asprepared NF membranes. Furthermore, the effects of MWCNTsPAMAM on the performance of the NF membranes were investigated. The as-fabricated NF membranes with an inner skin layer were used to separate heavy metals, and their longterm stability for the treatment of mine-wastewater was tested.

\section{Experimental}

\subsection{Materials}

Polyethersulfone (PES) capillary ultrafiltration (UF) membranes with three channels (pure water permeability $161 \mathrm{~L} \mathrm{~m}^{-2} \mathrm{~h}^{-1}$ $\mathrm{bar}^{-1}$ ) were self-made and used as the substrate. Piperazine (PIP, GR) was obtained from Sigma-Aldrich. Trimesoyl chloride (TMC, $\geq 98 \%$ ) was purchased from Qingdao Benzo Chemical Co., China. Carboxyl-functionalized MWCNTs (purity > $95 \mathrm{wt} \%$, $-\mathrm{COOH}$ content $3.86 \%$, and outer diameter $<8 \mathrm{~nm}$ ) were purchased from Shenzhen Nanotech Port Co. Ltd. Poly(amidoamine) (PAMAM, G4, $M_{\mathrm{w}}=14215 \mathrm{~g} \mathrm{~mol}^{-1}$, diameter $=4.4 \mathrm{~nm}$ ) were provided by Weihai CY Dendrimer Technology Co., Ltd, China. $N$-Hydroxysuccinimide (NHS) and $N$-(3-dimethylaminopropyl)- $N$-ethylcarbodiimide hydrochloride (EDC $\mathrm{HCl}$ ) were purchased from Aladdin Reagent Company (Shanghai, China) and used directly. Hexane, ethylene glycol, diethylene glycol, sucrose, PEG 400, PEG 600, $\mathrm{HCl}$ (33.6-38.6\%), $\mathrm{HNO}_{3}$ (65\%), and salts including $\mathrm{Na}_{2} \mathrm{SO}_{4}, \mathrm{MgSO}_{4}, \mathrm{MgCl}_{2}, \mathrm{NaCl}, \mathrm{Fe}_{2}\left(\mathrm{SO}_{4}\right)_{3}, \mathrm{FeCl}_{3}$, $\mathrm{CuCl}_{2}, \mathrm{CuSO}_{4}, \mathrm{Cu}\left(\mathrm{NO}_{3}\right)$, and $\mathrm{Pb}\left(\mathrm{NO}_{3}\right)_{2}$ were of analytical grade and provided from Sinopharm Chemical Reagent Co. Ltd. (China).

\subsection{Modification of MWCNTs}

MWCNTs-PAMAM were prepared (shown in Scheme 1) according to the study reported by Gu et al. ${ }^{26}$ Briefly, $600 \mathrm{mg}$ EDC $\mathrm{HCl}$ and $400 \mathrm{mg}$ NHS were added to $100 \mathrm{~mL}$ aqueous solution containing $0.2 \mathrm{~g}$ MWCNTs-COOH in an ice bath with ultrasonic treatment for $5 \mathrm{~min}$. Then, $10 \mathrm{~mL}$ PAMAM aqueous solution $\left(20 \mathrm{mg} \mathrm{mL}^{-1}\right.$ ) was added. The $\mathrm{pH}$ of the mixture was adjusted to 6-7 using HCl. After the reaction at $25{ }^{\circ} \mathrm{C}$ for $24 \mathrm{~h}$, MWCNTsPAMAM was purified using a $0.8 \mu \mathrm{m}$ filter. The residue was washed with plenty of deionized (DI) water and then freeze dried.

\subsection{Membrane fabrication}

The NF membranes were fabricated via IP, as schematically shown in Scheme 2. The detailed fabrication process was described in our previous study. ${ }^{\mathbf{1 6}}$ All the NF membranes with

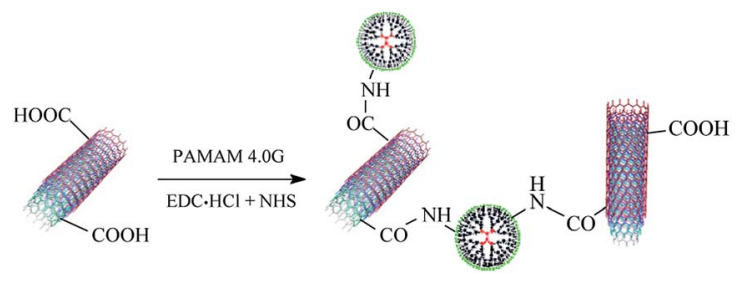

Scheme 1 Schematic showing the synthesis of MWCNTs-PAMAM. 
an inner skin layer were prepared with PIP $1.0 \%(\mathrm{w} / \mathrm{v})$, TMC $0.15 \%(\mathrm{w} / \mathrm{v})$, aqueous solution immersion time of $3 \mathrm{~min}$, reaction time of $15 \mathrm{~s}$ and heat treatment at $80{ }^{\circ} \mathrm{C}$ for $8 \mathrm{~min}$. The asfabricated NF membranes with an effective length of $50.3 \mathrm{~cm}$ were stored in DI water. The substrate and NF membranes prepared with PIP $(1.0 \%(\mathrm{w} / \mathrm{v}))$, PIP/MWCNTs-COOH $(1.0 \%$ (w/ v) $/ 0.05 \%(\mathrm{w} / \mathrm{v}))$, PIP/PAMAM (1.0 (w/v)\%/0.05\% (w/v)), and PIP/ MWCNTs-PAMAM $(1.0 \%(\mathrm{w} / \mathrm{v}) / 0.05 \%(\mathrm{w} / \mathrm{v}))$ in aqueous solution were labeled as M, MP, MPC, MPP and MPCP, respectively.

\subsection{Characterization}

The chemical composition and thermal stability of MWCNTsPAMAM were analyzed via X-ray photoelectron spectroscopy (XPS, VG Microlab II, UK), Fourier transform infrared spectroscopy (FTIR, Thermo Nicolet 6700) and thermogravimetric analysis (TGA, NETZSCH, STA409PC) over a temperature range of $30-800{ }^{\circ} \mathrm{C}\left(10{ }^{\circ} \mathrm{C} \min ^{-1}, \mathrm{~N}_{2}\right.$ atmosphere $)$.

The membrane samples were dried thoroughly prior to characterization. Attenuated total reflectance-Fourier transform infrared (ATR-FTIR) spectra were collected using a Nicolet 6700 spectrometer. The morphology and topology of the membranes were observed via FE-SEM (NOVA NanoSEM450, America) and AFM (IIIa MultiMode, America), respectively. Furthermore, the surface roughness of the membranes was evaluated via AFM. Water contact angle measurements were performed to analyze the hydrophilicity of the membranes at ambient temperature $\left(25 \pm 2{ }^{\circ} \mathrm{C}\right)$. The surface charge of the NF membranes was determined via the streaming potential method using an electrokinetic analyser (SurPASS, Anton Paar, Austria).

\subsection{Separation performance test}

The permeation and separation performances of the NF membranes were determined on a cross-flow apparatus at 4 bar. All the membranes were pre-filtrated with pure water at 4 bar for $30 \mathrm{~min}$ before the tests. The pure water flux of the membranes was calculated as follows:

$$
\mathrm{PWF}=\frac{Q}{A \times t}
$$

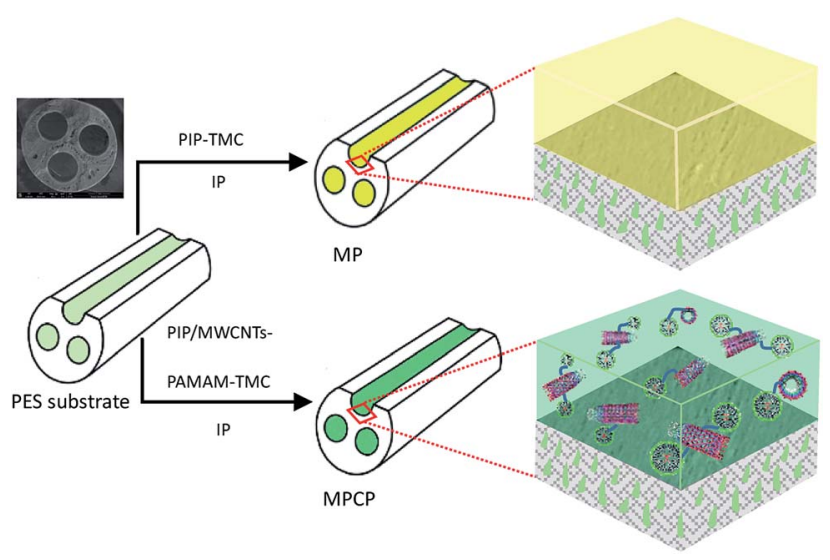

Scheme 2 Preparation process of NF membranes via IP on the inner surface of the substrate.
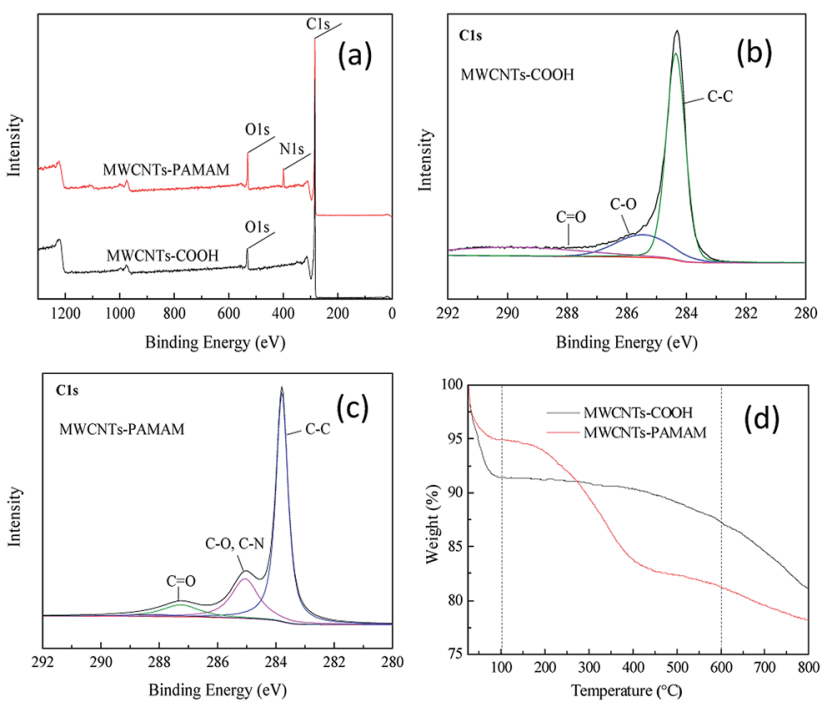

Fig. 1 Characterization of MWCNTs-PAMAM. (a) XPS wide-scan spectra, (b) C1s spectra of MWCNTs-COOH, (c) C1s spectra of MWCNTS-PAMAM and (d) TGA curves of MWCNTs-COOH and MWCNTS-PAMAM.

where $Q, A$ and $t$ denote the volume of permeate pure water (L), the effective area of the membrane $\left(\mathrm{m}^{2}\right)$ and the permeation time (h), respectively.

The pore size and pore distribution in the NF membranes were determined using aqueous solutions containing $200 \mathrm{mg} \mathrm{L}{ }^{-1}$ organics as the feed, ${ }^{27}$ and the separation performance of the NF membranes was measured using various salt solutions as the feed. The rejection can be calculated from the following equation:

$$
R=\left(1-\frac{C_{\mathrm{p}}}{C_{\mathrm{f}}}\right) \times 100 \%
$$

where $C_{\mathrm{p}}$ and $C_{\mathrm{f}}$ are the concentrations of the permeate and feed, respectively. The concentration of organics was obtained using a TOC analyzer (Shimadzu, Model TOCVPN, Japan). The concentration of the salt solutions $\left(\mathrm{Na}_{2} \mathrm{SO}_{4}, \mathrm{MgSO}_{4}, \mathrm{MgCl}_{2}\right.$ and $\mathrm{NaCl}$ ) was measured with an electrical conductivity meter (DDS-11A, Shanghai Neici Instrument Company, China) and the concentration of the heavy metals was determined via atomic absorption spectroscopy (INESA, 4510F, Shanghai Scientific Instrument Co., LTD) and ion chromatography (ICS1100, Thermo Fisher US). Each measurement was performed three times and the values were averaged. All filtration experiments were conducted at $25 \pm 2{ }^{\circ} \mathrm{C}$.

Table 1 Chemical composition of MWCNTs before and after modification

\begin{tabular}{llll}
\hline & \multicolumn{2}{l}{ Atom percent $(\mathrm{at} \%)$} \\
\cline { 2 - 4 } Sample & C1s & O1s & N1s \\
\hline MWCNTs-COOH & 94.40 & 5.60 & 0 \\
MWCNTs-PAMAM & 86.32 & 8.11 & 5.57
\end{tabular}




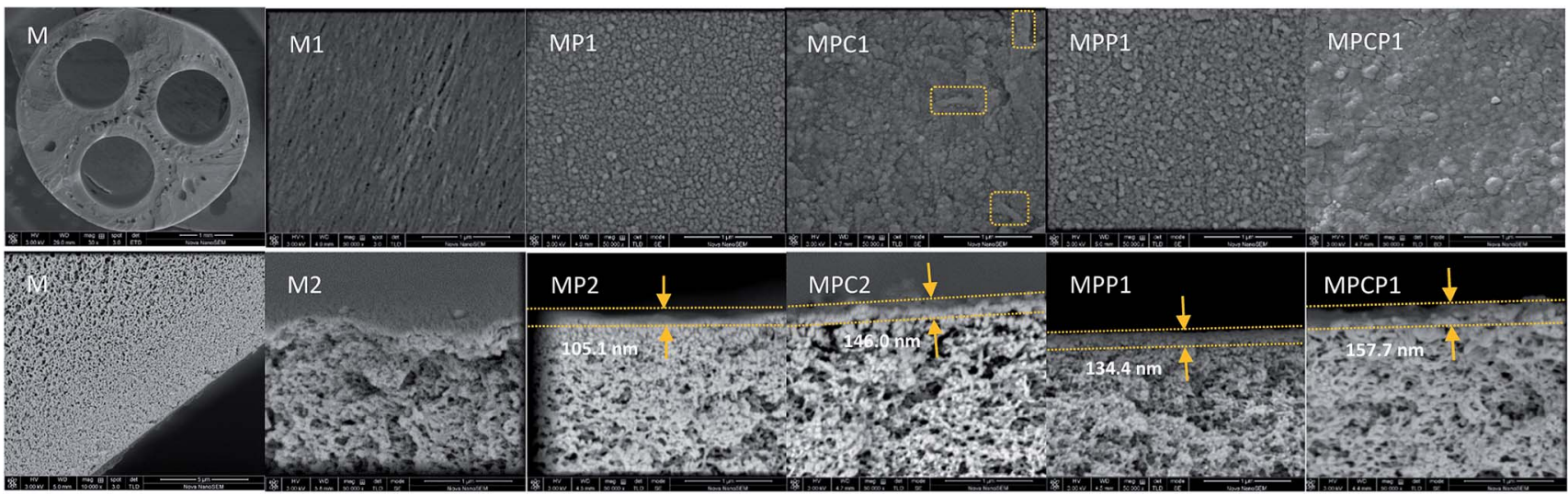

Fig. 2 FE-SEM images of the substrate and NF membranes. (1) Inner surface of membranes. (2) Cross-section of the membranes.

\section{Results and discussion}

\subsection{Characterization of modified MWCNTs}

XPS and TGA were employed to confirm the modification of MWCNTs-COOH, and the results are shown in Fig. 1. The element content from XPS is shown in Table 1. MWCNTs$\mathrm{COOH}$ contain $\mathrm{C} 1 \mathrm{~s}$ and $\mathrm{O} 1 \mathrm{~s}$, and no nitrogen content was detected. However, a $5.57 \%$ increment in N1s content for MWCNTS-PAMAM was observed, as shown in Fig. 1(a). As shown in Fig. 1(b), the high-resolution C1s spectra can be deconvoluted into three components: C-C or C-H $(284.35 \mathrm{eV})$, $\mathrm{C}-\mathrm{O}$ or $\mathrm{C}-\mathrm{N}(285.48 \mathrm{eV})$ and $\mathrm{C}(\mathrm{O}) \mathrm{O}(289.85 \mathrm{eV}) .^{28-30}$ The intensity of the peaks for $\mathrm{C}-\mathrm{O} / \mathrm{C}-\mathrm{N}$ and $\mathrm{C}(\mathrm{O}) \mathrm{O}$ in MWCNTsPAMAM increased, as shown in Fig. 1(c). Thus, the XPS results confirm the existence of PAMAM on MWCNTs-PAMAM. In addition, the FTIR spectra (Fig. S2 $\dagger$ ) also verify the chemical composition of MWCNTS-PAMAM.

The initial weight loss shown in the TGA curves in Fig. 1(d) is mainly due to the adsorbed moisture on MWCNTs. After this stage, the weight loss of MWCNTs-COOH and MWCNTsPAMAM is $4.2 \%$ and $13.7 \%$, respectively. The weight loss of $4.2 \%$ corresponds to the actual $-\mathrm{COOH}$ content of MWCNTs$\mathrm{COOH}$, which is $3.86 \%$. Thus, the $13.7 \%$ weight loss of MWCNTS-PAMAM confirms the existence of PAMAM. From the combined FTIR and TGA results, it can be concluded that PAMAM was immobilized on MWCNTs. In addition, MWCNTs-COOH and MWCNTs-PAMAM were well dispersed in the PIP aqueous solution (Fig. S1†).

\subsection{Membrane characterizations}

The formation of polyamide layers in the NF membranes was confirmed via ATR-FTIR (Fig. S5†). Compared with the spectrum of the substrate, in the spectrum of the NF membranes, the absorption band at around $3300 \mathrm{~cm}^{-1}$ is contributed by $-\mathrm{OH}$ and unreacted $-\mathrm{NH}$, and the peaks at $1625 \mathrm{~cm}^{-1}$ and $954 \mathrm{~cm}^{-1}$ are ascribed to the amide I and $\mathrm{C}-\mathrm{N}$ absorptions, respectively. The new band and peaks in the spectra of MP and MPCP confirm the formation of polyamide. In addition, the characteristic absorption of MP at $2964 \mathrm{~cm}^{-1}$ is attributed to the $-\mathrm{CH}_{2}$ provided by PIP. ${ }^{31}$ The absorption peak at $1439 \mathrm{~cm}^{-1}$ is ascribed to the stretching vibration of $\mathrm{C}-\mathrm{N},{ }^{32}$ and this peak is more intense in the spectrum of MPCP due to the abundant $\mathrm{C}-\mathrm{N}$ groups in PAMAM.

The surface and cross-section of the membranes were observed via FE-SEM, as shown in Fig. 2. The substrate exhibits a smooth surface with visible pores, while the NF membranes display a dense surface. It is interesting to note that MP and MPP have similar morphologies. There appear to be CNTs on the MPC surface, while bumps are detected on the MPCP surface. The polyamide layers of the NF membranes can be observed from the cross-section images, and the thickness of these layers increased after the incorporation of additives. The surface morphology of the NF membranes is determined by the nature of the monomers and additives, where the polyamide layers were formed via the reaction between the monomers in the aqueous and organic solutions. PIP and TMC are active monomers and a nodular surface morphology is characteristic for the polyamide layer formed by them. ${ }^{33}$ Although there are
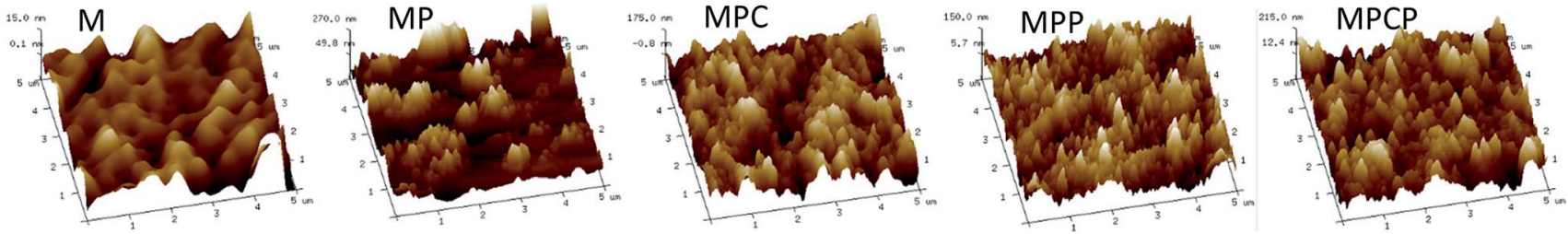

Fig. 3 AFM surface topology of the substrate and NF membranes. 


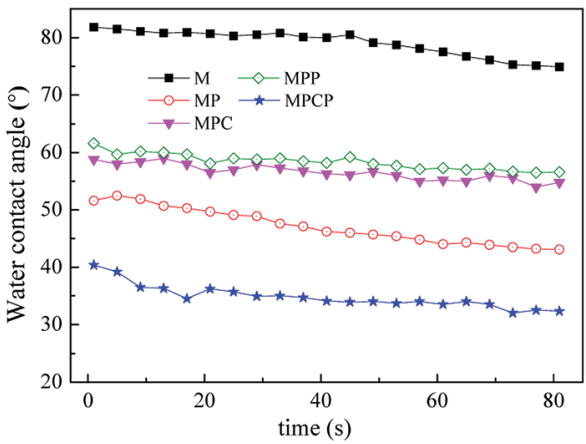

Fig. 4 Dynamic water contact angles of the substrate and NF membranes.

abundant active $-\mathrm{NH}_{2}$ groups in PAMAM, the larger molecular weight of PAMAM makes it difficult for it to migrate to the reaction interface during the IP process (15 s). Thus, MPP shows a similar surface morphology to MP. The additives MWCNTs$\mathrm{COOH}$ and MWCNTs-PAMAM changed the membrane surface morphology because they could hinder the mass transfer of the monomers. ${ }^{34}$ The larger size of MWCNTs also contributed to the membrane morphology. There appear to be MWCNTs on MPC, while there are none on MPCP, illustrating that MWCNTsPAMAM were embedded into the polyamide layer of MPCP. The increase in thickness of the polyamide layer was due to the gaps between the polyamide and the adjacent additives, ${ }^{35}$ which is also proven by the pore size of the membranes (Fig. 5).

The surface topology of the membranes was observed via AFM, as shown in Fig. 3. The substrate has a smooth surface, while rough ridge-and-valley-like polyamide layers were observed after IP. The surface roughness (Table 2) of the NF membranes follows the order MP $>$ MPCP $>$ MPC $>$ MPP. As mentioned above, the drastic reaction between PIP and TMC resulted in the rough surface of MP. MWCNTs in aqueous solution can retard this reaction, thus lowering the membrane roughness. It cannot be ignored that the larger size of MWCNTs is helpful in improving the surface roughness of the membranes. The PAMAM on MWCNTs-PAMAM can react with TMC (Fig. S3 and Table S1 $\dagger$ ). Moreover, the size of MWCNTsPAMAM is larger than that of MWCNTs-COOH; thus, the roughness of MPCP is higher than that of MPC. PAMAM can

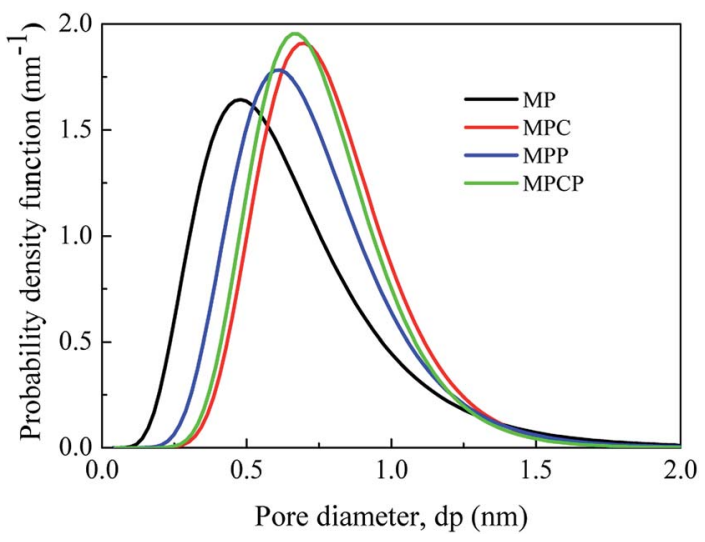

Fig. 5 Pore size distribution of the NF membranes.
Table 2 The mean pore size and MWCO of the NF membranes

\begin{tabular}{lcccc}
\hline Membrane & MP & MPC & MPP & MPCP \\
\hline Mean pore size (nm) & 0.589 & 0.755 & 0.687 & 0.727 \\
MWCO (Da) & 493 & 522 & 502 & 493
\end{tabular}

increase the viscosity of the aqueous solution, thus slowing down the IP reaction. Moreover, the large size of PAMAM makes it inferior to PIP in the competitive reaction with TMC. In addition, no MWCNTs contributed to the roughness of MPP. Therefore, MPP shows lower roughness compared with the other NF membranes.

Hydrophilicity of the NF membranes (Fig. 4) increased compared with that of the substrate because of the hydrophilic groups introduced via IP. ${ }^{36} \mathrm{NF}$ membrane hydrophilicity follows the order MPCP > MP > MPC > MPP, where MPC and MPP possess similar hydrophilicity. It is well known that membrane hydrophilicity is related to the groups on the membrane surface and its surface topology. Since the major groups on the NF membrane surface are amide groups, the hydrophilicity of the NF membranes is determined by their surface morphology. As mentioned above, the surface roughness of the membranes follows the order, MP $>$ MPCP $>$ MPC $>$ MPP. Although MP has a relatively rough surface, the hydrophilicity of $\mathrm{MP}$ is poorer than that of MPCP, which may be attributed to the incorporation of hydrophilic MWCNTs-PAMAM in the polyamide layer and the relatively loose separation layer of MPCP caused by MWCNTS-PAMAM. ${ }^{37}$

The pore size and pore distribution in the NF membranes were measured, and the results are shown in Table 2 and Fig. 5. The mean pore diameter of MP, MPC, MPP and MPCP is $0.589 \mathrm{~nm}, 0.755 \mathrm{~nm}, 0.687 \mathrm{~nm}$ and $0.727 \mathrm{~nm}$, respectively. Significantly, the mean pore size of the membranes increased after the introduction of additives into the selective layers. The increased pore size of MPC and MPCP is due to the introduced carbon nanomaterials, which increased the free volume of the polyamide layers. ${ }^{38,39}$ In addition, except for the network pores, some aggregate pores can be formed during IP with the incorporation of hyperbranched polymers. ${ }^{38}$ Thus, undoubtedly, MPP with incorporated PAMAM showed larger pores than MP. The sequence of membrane-pore diameter (MPC > MPCP > MPP) is attributed to the reaction between PAMAM and TMC during IP, which is verified in the ESI (Fig. S3 and Table S1 $\dagger$ ).

The top surface zeta potential, as shown in Fig. 6(a), confirms the negatively charged surface of the as-fabricated NF membranes. More specifically, the isoelectric point (IEP) of MPCP (5.9) is higher than that of MP (5.0), which verifies that positive sites were introduced into the polyamide layer of the NF membranes through the incorporation of MWCNTs-PAMAM. These positive sites are attributed to the numerous $-\mathrm{NH}_{2}$ groups provided by PAMAM.

A comparison test for the permeation and rejection performance of the NF membranes was conducted. As shown in Fig. 6(b), MP shows good rejection to $\mathrm{Na}_{2} \mathrm{SO}_{4}$, but its pure water flux is unsatisfactory. After the incorporation of MWCNTs$\mathrm{COOH}$, PAMAM or MWCNTs-PAMAM into the selective layer, 
(a)

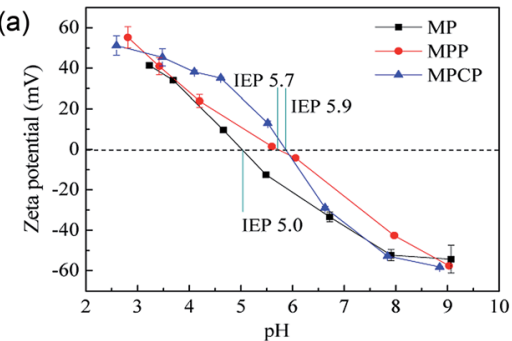

(b)

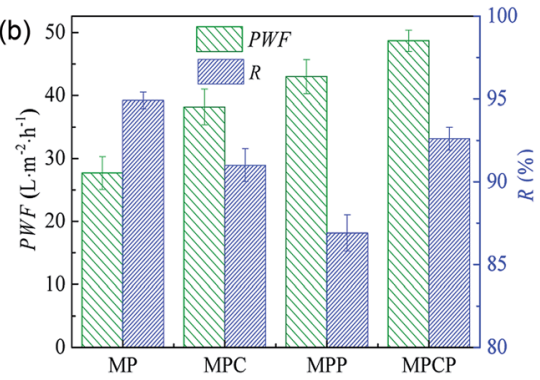

Fig. 6 (a) Top surface zeta potential of NF membranes and (b) permeation and rejection performances of the NF membranes for $2000 \mathrm{mg} \mathrm{L}^{-1} \mathrm{Na}_{2} \mathrm{SO}_{4}$

the NF membranes show improved permeability and slightly declined rejection. The additives improved the hydrophilicity or enlarged the mean pore size of the NF membranes, as discussed above; hence, the water flux of the NF membranes increased. The decrease in $\mathrm{Na}_{2} \mathrm{SO}_{4}$ rejection is ascribed to the increase in mean pore size and the positive sites on the membrane surface, which hinder the retention of $\mathrm{Na}_{2} \mathrm{SO}_{4}$. The mean pore size of MPC is close to the size of $\mathrm{SO}_{4}{ }^{2-}(0.379 \mathrm{~nm})$, and there are positive sites on the surface of both MPP and MPCP. Therefore, these NF membranes show relatively low rejection toward $\mathrm{Na}_{2} \mathrm{SO}_{4}$. The low $\mathrm{Na}_{2} \mathrm{SO}_{4}$ rejection of MPP may be caused by the higher positive charge density on its surface in $\mathrm{Na}_{2} \mathrm{SO}_{4}$ solution $(\mathrm{pH} \approx 7.0)$ compared to that on the other membranes. MPCP and MP almost have the same zeta potential when the solution $\mathrm{pH}$ is 7.0. The lower $\mathrm{Na}_{2} \mathrm{SO}_{4}$ rejection of MPCP is due to its larger pore size than that of MP. The $\mathrm{Na}_{2} \mathrm{SO}_{4}$ separation results illustrate that both size exclusion and electrostatic repulsion play a role in the filtration process.

\subsection{Separation performance of the MPMC membrane}

The separation performance of MPCP for different salts is shown in Fig. 7(a). The salt rejection of MPCP follows the order $\mathrm{Na}_{2} \mathrm{SO}_{4}>\mathrm{MgSO}_{4}>\mathrm{MgCl}_{2}>\mathrm{NaCl}$, which is consistent with that of MP. In addition, MPCP shows higher rejection toward $\mathrm{MgSO}_{4}, \mathrm{MgCl}_{2}$ and $\mathrm{NaCl}$, particularly to $\mathrm{MgCl}_{2}$ and $\mathrm{NaCl}$, compared with MP. Notably, the rejection discrepancies between $\mathrm{Na}_{2} \mathrm{SO}_{4}, \mathrm{MgSO}_{4}$ and $\mathrm{MgCl}_{2}$ are not apparent for MPCP. The NF membranes prepared in this study are generally negatively charged, which confirms that MPCP has high $\mathrm{SO}_{4}{ }^{2-}$ rejection..$^{40}$ The positive sites on the MPCP surface are responsible for $\mathrm{Mg}^{2+}$ rejection, as shown in Fig. 7(c). The higher $\mathrm{NaCl}$ rejection of MPCP can also be explained by the positive sites on its surface since positively charged NF membranes usually have high $\mathrm{NaCl}$ rejection. ${ }^{\mathbf{4 1 , 4 2}}$ The abovementioned phenomenon (a)

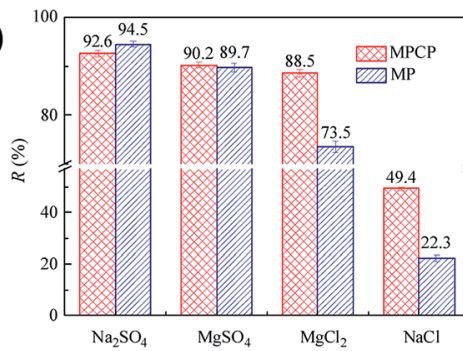

(b)
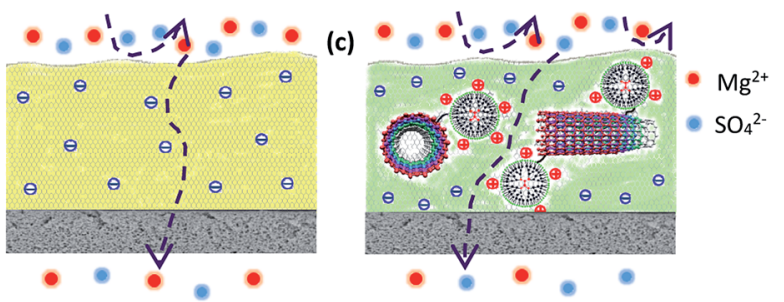

Fig. 7 (a) Separation performance of the MPCP membrane for inorganic salts $\left(2000 \mathrm{mg} \mathrm{L}^{-1}\right)$. The mechanisms of salt permeation through the (b) MP and (c) MPCP membrane.

illustrates that MPCP, which is a negatively charged NF membrane, also possesses the properties of positively charged NF membranes.

\subsection{Applications of the MPCP membrane for heavy metal ion removal}

The separation ability of MPCP toward typical toxic or potentially toxic metal ions was evaluated and shown in Fig. 8. MPCP shows above $95 \%$ rejection to $\mathrm{CuSO}_{4}, \mathrm{CuCl}_{2}, \mathrm{Fe}_{2}\left(\mathrm{SO}_{4}\right)_{3}$ and $\mathrm{FeCl}_{3}$, and its rejection to sulfates and $\mathrm{Cu}^{2+}$ is higher than that of chloride salts and $\mathrm{Fe}^{3+}$, respectively. In addition, its $\mathrm{Cu}\left(\mathrm{NO}_{3}\right)_{2}$ rejection is much higher than $\mathrm{Pb}\left(\mathrm{NO}_{3}\right)_{2}$. As mentioned above, there are negative groups and positive sites on the MPCP surface and its mean pore size is smaller than the size of these heavy metals and $\mathrm{SO}_{4}{ }^{2-}$. Hence, MPCP shows better rejection to sulfates, $\mathrm{Cu}^{2+}$ and $\mathrm{Fe}^{3+}$ due to the Donnan effect and size exclusion. It should be noted that although $\mathrm{Fe}^{3+}(0.428 \mathrm{~nm})$ has a larger hydrated ionic radius than $\mathrm{Cu}^{2+}(0.419 \mathrm{~nm})$, the rejection of $\mathrm{Fe}^{3+}$ is lower than that of $\mathrm{Cu}^{2+}$, which may be caused by the solution $\mathrm{pH}$. The effect of solution $\mathrm{pH}$ on salt rejection will

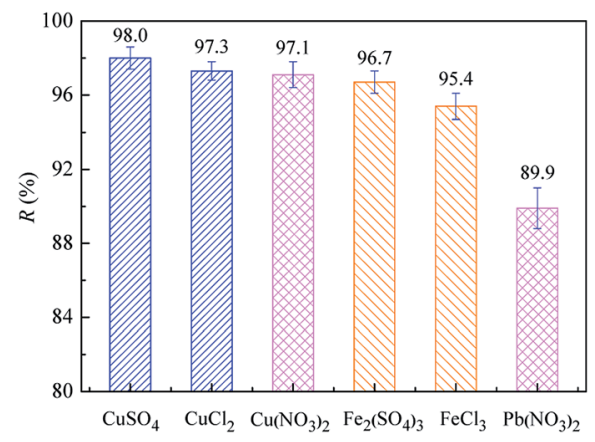

Fig. 8 Separation performance of MPCP for heavy metal ions $\left(\mathrm{Cu}^{2+}\right.$, $\mathrm{Fe}^{3+}$ and $\left.\mathrm{Pb}^{2+}\right)$. The concentration of all the heavy metal ions was $300 \mathrm{mg} \mathrm{L}^{-1}$, and the solution $\mathrm{pH}$ for $\mathrm{Pb}^{2+}, \mathrm{Cu}^{2+}$ and $\mathrm{Fe}^{3+}$ was 5.0, 5.0 and 2.0 , respectively. 
(a)

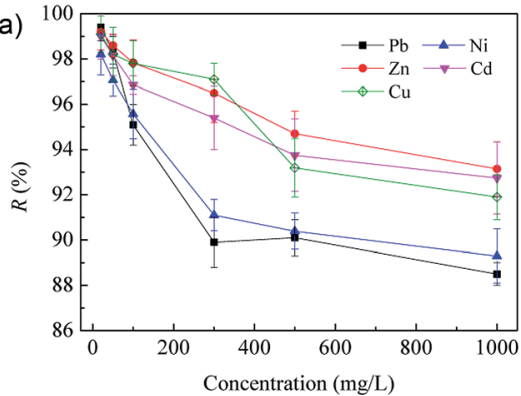

(b)

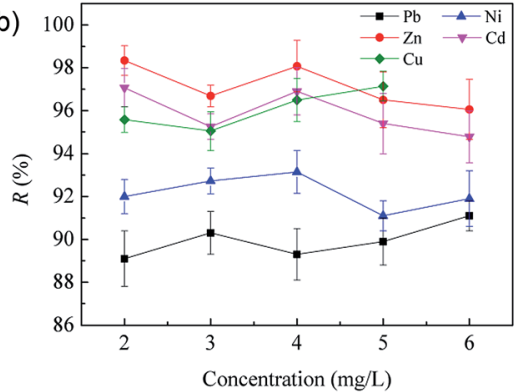

Fig. 9 Separation performance of the MPCP membrane for heavy metal ions. (a) $\mathrm{pH}=5.0,25^{\circ} \mathrm{C}$ and (b) $300 \mathrm{mg} \mathrm{L}^{-1}, 25^{\circ} \mathrm{C}$; $\mathrm{pH}$ was adjusted using $\mathrm{HNO}_{3}$.

be discussed in detail later. The lower rejection of $\mathrm{Pb}^{2+}$ may be caused by its smaller hydrated radius $(0.401 \mathrm{~nm})$ than that of $\mathrm{Cu}^{2+} .32$

The separation performance of MPCP for different heavy metals was further tested, and the effects of ion concentration and solution $\mathrm{pH}$ were investigated. As shown in Fig. 9, the heavy metal rejection decreased with an increase in ion concentration, which follows the sequence $\mathrm{Zn}^{2+}(0.430 \mathrm{~nm})>\mathrm{Cd}^{2+}(0.425 \mathrm{~nm})>$ $\mathrm{Cu}^{2+}(0.419 \mathrm{~nm})>\mathrm{Ni}^{2+}(0.404 \mathrm{~nm})>\mathrm{Pb}^{2+}(0.401 \mathrm{~nm})$ at higher concentrations $\left(\geq 500 \mathrm{mg} \mathrm{L}^{-1}\right)$. However, the heavy metal rejection showed an irregular fluctuation with an increase in solution $\mathrm{pH}$. The surface of MPCP is positively charged when solution $\mathrm{pH}<5.9$ (Fig. 6(a)). Hence, MPCP shows good rejection for heavy metal cations. The high rejection of heavy metals at a low ion concentration may be partially ascribed to membrane adsorption. Although $\mathrm{Pb}^{2+}$ adsorption on MPCP is just $2.4 \mathrm{mg}$ per module $\left(66.0 \mathrm{~cm}^{2}\right.$ effective membrane area) (Fig. $\left.\mathrm{S} 8 \dagger\right)$, it contributes to the rejection of heavy metals when the solution concentration is below $300 \mathrm{mg} \mathrm{L^{-1 }}$. When the solution concentration is above $500 \mathrm{mg} \mathrm{L} \mathrm{L}^{-1}$, the contribution of adsorption may be negligible. Thus, the adsorption can be precluded as the mechanism for membrane retention. In addition, the rejection of heavy metals mainly depends on size exclusion and the Donnan effect since MPCP has a positively charged surface at pH 5 and a pore diameter smaller than the size of heavy metal ions. The surface charge density of MPCP would be screened by the counterions at a high concentration, that is, a high concentration of ions may weaken the Donnan exclusion and lower the membrane rejection. ${ }^{1,43}$ The different rejection of heavy metals is mainly due to their hydrated ionic radius.

The higher charge density of MPCP at lower pH (Fig. 6(a)) is favorable for the membrane to resist heavy metals. It is notable that a low pH leads to dense packing in the outer shell of PAMAM, which is driven by the strong intramolecular hydrogen bonding within the dendrimer-water-counterion systems. ${ }^{44}$ In addition, the dense shell of PAMAM reduces the positive sites, which is unfavorable for cation rejection. In addition, the shrinking of PAMAM at a low $\mathrm{pH}$ would decrease the radius of gyration, thus increasing the porosity of the separation layer, which is also unfavorable for ion rejection. The increase in surface positive charge of MPCP and the shrinking of PAMAM eventually caused a fluctuation in the rejection of heavy metals versus solution $\mathrm{pH}$ value.

A comparison of the MPCP membrane developed in the current study with some commercially available and lab-made NF membranes is presented in Table 3. It can be found that MPCP has higher pure water permeability and better $\mathrm{Pb}^{2+}$ rejection than that of some positively charged NF membranes.

Furthermore, the practical separation ability of MPCP for wastewater was tested. The wastewater was collected from a mine located in Tongling City, Anhui Province, which had already been processed. The collected wastewater was first filtrated using the three-channel capillary UF membranes, which were used as the substrate. Then, the permeate was used as the feed to test the separation performance of the as-prepared NF membrane.

The metal ions in the feed included $\mathrm{Cu}^{2+}\left(78.83 \mathrm{mg} \mathrm{L}^{-1}\right), \mathrm{Ni}^{2+}$ (16.56 $\left.\mathrm{mg} \mathrm{L}^{-1}\right), \mathrm{Zn}^{2+}\left(18.28 \mathrm{mg} \mathrm{L}^{-1}\right), \mathrm{Pb}^{2+}\left(9.96 \mathrm{mg} \mathrm{L}^{-1}\right)$, and $\mathrm{Na}^{+}$ $\left(372.76 \mathrm{mg} \mathrm{L}^{-1}\right)$. In addition, the anions in the feed were $\mathrm{SO}_{4}{ }^{2-}$ $\left(10.56 \mathrm{mg} \mathrm{L}^{-1}\right)$ and $\mathrm{Cl}^{-}\left(706.31 \mathrm{mg} \mathrm{L}^{-1}\right)$. The $\mathrm{pH}$ of the feed was 4.77. As shown in Fig. 10, MPCP showed a stable separation performance during the 25 day test. The solution flux stabilized in the range of $29-32 \mathrm{~L} \mathrm{~m}^{-2} \mathrm{~h}^{-1}$, and the heavy metal rejection was maintained above $80 \%$, displaying good separation ability

Table 3 Comparison of the separation performances of MPCP with that of other NF membranes

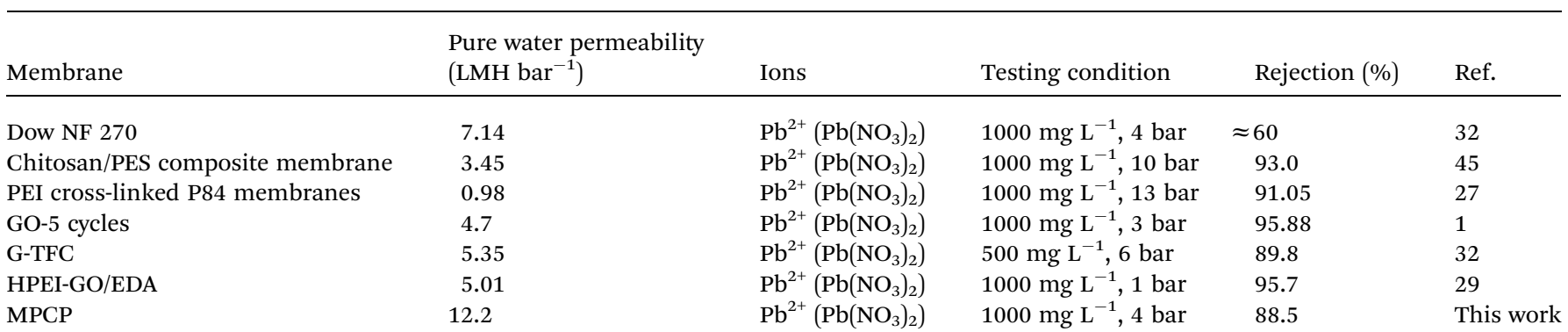




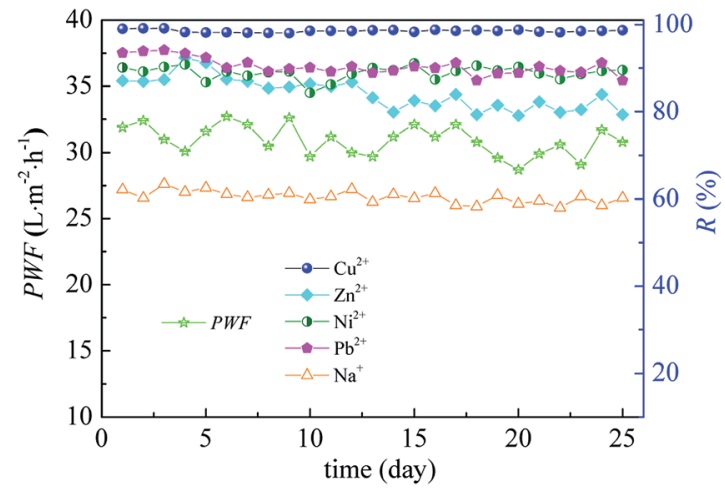

Fig. 10 Separation stability of MPCP toward mine wastewater (4 bar, $\mathrm{pH}=4.77)$.

for the mining wastewater. The rejection of heavy metals mainly followed the order $\mathrm{Cu}^{2+}>\mathrm{Pb}^{2+} \approx \mathrm{Ni}^{2+}>\mathrm{Zn}^{2+}$, which is consistent with the size of the ions in terms of their hydrated radius, except $\mathrm{Zn}^{2+}$. The stable solution flux is attributed to the rigid MWCNTs, which can sustain membrane pore structure during pressure driven filtration, ${ }^{35,46}$ and the good hydrophilicity of MPCP. MPCP is positively charged at $\mathrm{pH} 4.77$ and its mean pore size is smaller than the size of heavy metal ions; thus, MPCP shows good rejection to these heavy metal ions. The low rejection of $\mathrm{Zn}^{2+}$ may be ascribed to its tetrahedral coordination geometry with water molecules, ${ }^{35}$ which would decrease the electrostatic repulsion between $\mathrm{Zn}^{2+}$ and the charge on the MPCP surface due to the combination of the water molecules with $\mathrm{Zn}^{2+}$. Moreover, although $\mathrm{Cu}^{2+}, \mathrm{Pb}^{2+}$ and $\mathrm{Ni}^{2+}$ favour a square-planar coordination geometry and they have similar electrostatic interactions with the MPCP surface, size exclusion decides the rejection. The divalent cations in the wastewater would screen the negative charge on the MPCP surface, resulting in high $\mathrm{Na}^{+}$rejection. Additionally, the high rejection of $\mathrm{Na}^{+}$ is also ascribed to the positively charged membrane surface at $\mathrm{pH}$ 4.77. This phenomenon further verifies that both size exclusion and electrostatic repulsion play a role during filtration. The results mentioned above illustrate that MPCP fabricated in this study with incorporated MWCNTs-PAMAM has potential in treating heavy metal wastewater.

\section{Conclusion}

MWCNTS-PAMAM were successfully synthesized and incorporated into NF membranes via IP, and the hydrophilicity of the modified NF membranes with an inner skin layer increased. The water flux of the most optimal MPCP membrane is $12.2 \mathrm{~L}$ $\mathrm{m}^{-2} \mathrm{~h}^{-1} \mathrm{bar}^{-1}$, which is 1.7-times higher than that of the unmodified NF membranes, while its $\mathrm{Na}_{2} \mathrm{SO}_{4}$ rejection exhibited a slight decline (from $94.9 \%$ to $92.6 \%$ ). The incorporation of MWCNTS-PAMAM introduced positive sites into the polyamide layer, which endowed the MPCP membrane with high rejection for both sulfates and metal cations. Moreover, the as-prepared MPCP membrane exhibits good removal performance for heavy metals and stable separation ability during a 25 day test.
Overall, the results indicate the potential applicability of the MPCP membrane as a highly efficient and reusable material for heavy metal removal and water reclamation.

\section{Conflicts of interest}

There are no conflicts to declare.

\section{Acknowledgements}

The authors are thankful for the financial support received from the National Science and Technology Support Project of China (2014BAB07B01 and 2015BAB09B01), the Fundamental Research Funds for the Central Universities (WA1814009), the National Science and the Consulting Program of the Chinese Academy of Engineering (2017-XZ-08-04-02).

\section{References}

1 Y. Zhang, S. Zhang, J. Gao and T.-S. Chung, J. Membr. Sci., 2016, 515, 230-237.

2 D. L. S. Bassam, Z. Shakhashiri and J. L. Schnoor, Chemical and Engineering News Archives, 2013, 91, 37.

3 E. V. H. Annajawor, Environ. Sci. Technol., 2010, 44, 25702576.

4 J. Ma, G. Zhou, L. Chu, Y. Liu, C. Liu, S. Luo and Y. Wei, ACS Sustain. Chem. Eng., 2017, 5, 843-851.

5 H. Yoo and S.-Y. Kwak, J. Membr. Sci., 2013, 448, 125-134.

6 B. Li, F. Zhou, K. Huang, Y. Wang, S. Mei, Y. Zhou and T. Jing, Sci. Rep., 2017, 7, 43082.

7 Z. Rao, K. Feng, B. Tang and P. Wu, ACS Appl. Mater. Interfaces, 2017, 9, 2594-2605.

8 M. R. Moghbeli, A. Khajeh and M. Alikhani, Chem. Eng. J., 2017, 309, 552-562.

9 J. Wu, Z. Wang, W. Yan, Y. Wang, J. Wang and S. Wang, J. Membr. Sci., 2015, 496, 58-69.

10 G.-R. Xu, J.-N. Wang and C.-J. Li, Desalination, 2013, 328, 83100.

11 C. Wu, S. Liu, Z. Wang, J. Zhang, X. Wang, X. Lu, Y. Jia, W.-S. Hung and K.-R. Lee, J. Membr. Sci., 2016, 517, 64-72.

12 W. Fang, L. Shi and R. Wang, J. Membr. Sci., 2014, 468, 52-61. 13 D. Wu, S. Yu, D. Lawless and X. Feng, React. Funct. Polym., 2015, 86, 168-183.

14 C. Ba and J. Economy, J. Membr. Sci., 2010, 362, 192-201. 15 W.-P. Zhu, J. Gao, S.-P. Sun, S. Zhang and T.-S. Chung, J. Membr. Sci., 2015, 487, 117-126.

16 H.-Z. Zhang, Z.-L. Xu, Y.-J. Tang and H. Ding, J. Membr. Sci., 2017, 527, 111-120.

17 X. Kong, Y. Zhang, S.-Y. Zeng, B.-K. Zhu, L.-P. Zhu, L.-F. Fang and H. Matsuyama, J. Membr. Sci., 2016, 518, 141-149.

18 Y. Pan, R. Xu, Z. Lü, S. Yu, M. Liu and C. Gao, J. Membr. Sci., 2017, 523, 282-290.

19 Y. Gou, X. Yang, L. He, X. Xu, Y. Liu, Y. Liu, Y. Gao, Q. Huang, K. Liang, C. Ding, J. Li, C. Zhao and J. Li, Polym. Chem., 2017, 8, 4264-4279.

20 Y. Mansourpanah and Z. Jafari, React. Funct. Polym., 2015, 93, 178-189. 
21 M. F. Jimenez-Solomon, Q. Song, K. E. Jelfs, M. MunozIbanez and A. G. Livingston, Nat. Mater., 2016, 15, 760-767.

22 F. Y. Zhao, Y. L. Ji, X. D. Weng, Y. F. Mi, C. C. Ye, Q. F. An and C. J. Gao, ACS Appl. Mater. Interfaces, 2016, 8, 6693-6700.

23 J. Lee, Y. Ye, A. J. Ward, C. Zhou, V. Chen, A. I. Minett, S. Lee, Z. Liu, S.-R. Chae and J. Shi, Sep. Purif. Technol., 2016, 163, 109-119.

24 S. M. Xue, Z. L. Xu, Y. J. Tang and C. H. Ji, ACS Appl. Mater. Interfaces, 2016, 8, 19135-19144.

25 M. H. Davood, A. Farahani, D. Hua and T.-S. Chung, J. Membr. Sci., 2018, 548, 319-331.

26 Y. Gu, Y. Guo, C. Wang, J. Xu, J. Wu, T. B. Kirk, D. Ma and W. Xue, Mater. Sci. Eng. C, 2017, 70, 572-585.

27 J. Gao, S.-P. Sun, W.-P. Zhu and T.-S. Chung, J. Membr. Sci., 2014, 452, 300-310.

28 T. Liu, X. Han, Y. Wang, L. Yan, B. Du, Q. Wei and D. Wei, J. Colloid Interface Sci., 2017, 508, 405-414.

29 Y. Zhang, S. Zhang and T. S. Chung, Environ. Sci. Technol., 2015, 49, 10235-10242.

30 A. Zirehpour, A. Rahimpour, A. Arabi Shamsabadi, M. Sharifian Gh and M. Soroush, Environ. Sci. Technol., 2017, 51, 5511-5522.

31 Y. P. Tang, S. Yuwen, T. S. Chung, M. Weber, C. Staudt and C. Maletzko, J. Membr. Sci., 2016, 510, 112-121.

32 M. Li, Z. Lv, J. Zheng, J. Hu, C. Jiang, M. Ueda, X. Zhang and L. Wang, ACS Sustain. Chem. Eng., 2017, 5, 784-792.

33 H. Li, W. Shi, Y. Zhang, Q. Du, X. Qin and Y. Su, Sep. Purif. Technol., 2016, 166, 240-251.
34 H.-Z. Zhang, Z.-L. Xu, H. Ding and Y.-J. Tang, Desalination, 2017, 420, 158-166.

35 F. Soyekwo, Q. Zhang, R. Gao, Y. Qu, R. Lv, M. Chen, A. Zhu and Q. Liu, J. Mater. Chem. A, 2017, 5, 583-592.

36 T. Tong, S. Zhao, C. Boo, S. M. Hashmi and M. Elimelech, Environ. Sci. Technol., 2017, 51, 4396-4406.

37 D. J. Miller, D. R. Dreyer, C. W. Bielawski, D. R. Paul and B. D. Freeman, Angew. Chem., Int. Ed. Engl., 2017, 56, 4662-4711.

38 X. Kong, Z.-L. Qiu, C.-E. Lin, Y.-Z. Song, B.-K. Zhu, L.-P. Zhu and X.-Z. Wei, J. Mater. Chem. A, 2017, 5, 7876-7884.

39 X. Gao, Y. Li, X. Yang, Y. Shang, Y. Wang, B. Gao and Z. Wang, J. Mater. Chem. A, 2017, 5, 19875-19883.

40 J. Zhu, L. Qin, A. Uliana, J. Hou, J. Wang, Y. Zhang, X. Li, S. Yuan, J. Li, M. Tian, J. Lin and B. Van der Bruggen, ACS Appl. Mater. Interfaces, 2017, 9, 1975-1986.

41 Y. C. Xu, Z. X. Wang, X. Q. Cheng, Y. C. Xiao and L. Shao, Chem. Eng. J., 2016, 303, 555-564.

42 Y. Cui, Z.-K. Yao, K. Zheng, S.-Y. Du, B.-K. Zhu, L.-P. Zhu and C.-H. Du, J. Membr. Sci., 2015, 492, 187-196.

43 J. Miao, R. Zhang and R. Bai, J. Membr. Sci., 2015, 493, 654663.

44 Y. Liu, V. S. Bryantsev, M. S. Diallo and W. A. Goddard III, J. Am. Chem. Soc., 2009, 131, 2798-2799.

45 S. Zhang, M. H. Peh, Z. Thong and T.-S. Chung, Ind. Eng. Chem. Res., 2015, 54, 472-479.

46 J. Zhu, A. Uliana, J. Wang, S. Yuan, J. Li, M. Tian, K. Simoens, A. Volodin, J. Lin, K. Bernaerts, Y. Zhang and B. Van der Bruggen, J. Mater. Chem. A, 2016, 4, 13211-13222. 